\title{
CMC and Its Psychological Motives in Communication: A Case Study in Japanese Mobile Phone-E-Mail
}

\author{
Noboru Sakai ${ }^{1}$ \\ ${ }^{1}$ The Center for English as a Lingua Franca, Tamagawa University, Tokyo, Japan \\ Correspondence: Noboru Sakai, The Center for English as a Lingua Franca, Tamagawa University, Tokyo, Japan. \\ Tel: 81-90-1436-5797. E-mail: noboru.sakai@uqconnect.edu.au
}

Received: March 20, 2018

Accepted: June 25, $2018 \quad$ Online Published: July 27, 2018

doi:10.5539/ass.v14n8p1

URL: https://doi.org/10.5539/ass.v14n8p1

\begin{abstract}
The study investigates 60 young people aged 18 to 30 who are familiar with mobile phone e-mail (Keitai-mail) practices in Japan (a 1-to-1 ratio of male and female, the participants' domiciles in several big Japanese cities) using a questionnaire on how they feel about CMC communication, in order to elucidate one type of widely used communication methods in the time the IT has been offering the variety of communication platforms. The result shows that senders are ruled by the norms entailed in Keitai-mail communication: Keitai-mail should be responded to immediately but should also be a complete sentence or message. In addition, the expressions used in Keitai-mail vary based on the interlocutors, making Keitai-mail a heavily context-dependent communication medium.
\end{abstract}

Keywords: Computer Mediated Communication (CMC) E-Mail, Japanese, user psychology

\section{Introduction}

$\mathrm{CMC}$ is an inseparable part of our daily communication, with this communication type occurring even more than face-to-face communication today. Reflecting on this social system depending on CMC, this study investigates the underlying motivation for using $\mathrm{CMC}$ as communication tool in order to deepen the communication of today's human beings. To do so this study investigates Japanese mobile phone e-mail (Keitai-mail) as an example by analysing a relatively large real talk corpus.

In today's Japan, Keitai are a tool that people always have with them, anywhere, at any time (Hayashi, 2007), and they also provide a communication space where users, especially teenagers, can achieve freedom from social restrictions (Ito \& Okabe, 2005b). At the same time, some people depend on Keitai and some of then too heavily counting as they feel anxiety if they do not have their Keitai with them all the time, feel sad if they do not receive an e-mail in reply to one of theirs, feel lonely without their Keitai and anxious when they cannot turn on their Keitai (Ikemoto \& Shiomi, 2006). For some people, Keitai-mail are a method of overcoming sadness when they are lonely or sad (Tomari, 2004; Ida, 2003), and therefore, the more people fear loneliness, the more they use Keitai-mail (Nakamura, 2003). This tendency appears more strongly in men (Tomari, 2004). These cases show that the status of Keitai as a central part of daily life in Japanese people.

In today's Japanese society, people are connected through Keitai (Fujimoto, 2006): people gauge their friendships based on how frequently they exchange Keitai-mail (Ono \& Tokuda, 2005). At the same time, Miyake (2002) further argues that while a relationship via Keitai-mail seems close, it is actually weak because people need to constantly reaffirm their connection and friendship, otherwise they feel anxious. Miyake (2003a) also gives another interpretation, that Keitai-mail provide both intimacy and distance at the same time, which corroborates the communication tendency among young Japanese people that they want to have friends but not to be in a deep or serious relationship. Under this sensitive communication phenomena of Keitai-use, further investigation from field study will deepen the understand of psychological aspects of Keitai-mail communication which has rooted on Japanese daily life but not a complete trust in terms of communication methods with others.

As the short discussion above indicates, people are experiencing a tumult of change in their communication methods using CMC, which have also changed rapidly. At the same time, people need some time to accept it and may today be in a dilemma as to whether to use traditional or new communication norms. Among these IT-based communication platforms, Keitai-mail, or other e-mail available in mobile phone applications and chat based 
applications such as Line of Facebook messenger, is used differently even though they would have the similar basic specifications. Therefore, to analyse psychological aspects of this medium would be a milestone in describing a gigantic field of computer uses in this IT era.

\section{Literature Review}

This section reviews past research studies which focus on psychological aspects of Keitai-mail communication from three viewpoints: general psychological factors, the semi-synchronised nature of Keitai-mail, and emoticons section.

\subsection{Types of Interloctors}

The first is the psychological factors reflected in language use in Keitai-mail. There is a relationship between content of e-mail and interlocutor - people use certain expressions in sending messages to certain people and if this norm is violated, they feel uncomfortable. Riviere and Licoppe (2005) discuss this point and explain three types of social relationship and how Japanese people distinguish language use in e-mail based on them. The first relationship encompasses family members and close friends whom one meets every day in school or a workplace and has opportunities to go out with; the second relationship involves people whom one tends not to meet or is not as intimate with as the members of the first group, such as former classmates or colleagues; the third relationship is with acquaintances with whom one does not have regular communication and closeness. Based on these three relationships, people adjust their behaviour from carefree to serious, or casual to formal, including their use of language. Keitai-mail themselves show this tendency: if senders feel greater distance, they use more formal language, which is a reflection of etiquette in real life social practice in Japan.

For a more concrete example, Kato, Kato, and Akahori's (2006a) report shows that people perceive an interlocutor to be honest when they receive an e-mail which consists of formal language; on the other hand, they feel closeness when they receive e-mail with speech-like language and emoticons. These two variables are a trade-off. Therefore, people feel good when they receive e-mails using speech-like language or emoticons from their close friends.

Moreover, Sato, Kato and Kato (2008) investigate how the content of Keitai-mail as well as the sender induces feelings in the recipient, and further how recipients choose to either express sympathy or restrict their emotion when replying to these e-mails. The emotions investigated are enjoyment, sadness, anger, and guilt; groups of senders are close friends, non-close friends, close teachers, and non-close teachers. The results show that if the content involves enjoyment, recipients feel enjoyment as well. They also tend to express sympathy regardless of who the sender is, but the closer the sender, the more strongly the recipient feels this. As for sadness, when senders are close friends, recipients try to express their sympathy to them. This is because intimacy with close friends is influential in inducing the emotion of strong sadness.

Anger expressed in Keitai-mail generally induces sadness and anger, and entails sympathy from all groups of senders, but if senders are people close to the recipient, the feeling occurs more strongly. At the same time, recipients also restrict their feeling if senders are close friends; this is an effect of intimacy. When recipients feel guilty after reading Keitai-mail, they try to alleviate the sender's feeling of anger through expressing their guilt across any of the four sender groups. At the same time, if senders are close friends, recipients also try to alleviate these senders' anger by conveying their own sadness, also an effect of intimacy. As this study shows, complex psychological activity occurs when reading Keitai-mail based both on the content and on who sends the Keitai-mail; this is a key factor in analysing Keitai-mail to discover why people use particular language based on a certain psychological state.

\subsection{Semi-synchronous Nature}

Second one is semi-synchronous nature of Keitai-mail. Even though Keitai-mail have a conversational nature, the communication is still in one direction, so this provides a feeling of comfort because people can communicate with others at their own pace and sometimes it leads to too much use of Keitai-mail or addiction to it (Amasa et al, 2004). Keitai-mail are a sender-centred communication medium. However, recipients also feel pressure to reply to e-mail immediately, or senders feel anxiety if they do not receive a reply quickly (Amasa et al 2004) because it is rude (Fujimoto, 2006). Hayashi (2007) notes that people hold the premise in Keitai-mail communication that it is a continuous exchange of messages even though it is not really synchronous communication. In other words, Keitai-mail carry the expectation of a reply (Suzuki, 2005).

Reflecting on this nature of e-mail communication, some senders feel angry when they do not receive a reply e-mail within a relatively short time, in particular compared with PC e-mail, and this shows that people expect more synchronised communication through Keitai-mail (Kato et al., 2006b). On this point, Fujimoto (2006) 
discusses Keitai-mail as the textualised voice of mobile phone communication, implying that Keitai-mail messages should receive a swift reply because the interlocutors have their 'Keitai (portable)' device for communication on their persons. That the phenomenon of a late reply being perceived as rude is already deep rooted among young people can be seen in the episode reported in Kitani (2003) when his student prioritised sending a reply to a message received even when he/she was talking with the professor, giving the reason that it required a quick response. Kato et al.'s (2006b) study also shows that when people receive e-mail consisting of a short message, they also feel angry and sad.

These points reveal an interesting aspect of the nature of Keitai-mail communication: even though Keitai-mail are an asynchronous communication, people feel or expect them to be synchronous communication, but if they use them as a synchronous communication medium and receive a short message in reply to their previous message, they feel angry or sad; this means that an e-mail is an individual message, a message of asynchronous communication. Fujimoto (2006) finds that in Keitai-mail communication, when senders do not receive a quick reply, people do not expect that the recipient has not read their e-mail, because they assume the recipient has their 'Keitai (portable)' with them at all times; rather, they think the recipient cannot or does not reply to the mail for some other reason. As shown above, Keitai-mail communication contains both synchronous and asynchronous aspects of communication, so Keitai-mail communication can be said to be semi-synchronous communication, similar to Internet chat (Uchida, 2004).

As discussed above, Keitai-mail are an easy and convenient method of communication and this further provides users with opportunities to write and read Japanese. At the same time, however, as Katayama (2003) argues, Keitai-mail communication is more a matter of textualised oral communication than the pure written communication found in letters, with the result that the content of e-mail is rather plain and is not the result of deep and logical thinking in composition. Baron (2008) further describes this phenomenon: language on the Internet is written in format but has the nature of spoken language in informal settings, which results from lack of effort in composition. The Keitai interface also influences the language of Keitai-mail. Some studies show that the small screen size of Keitai affects the creation of e-mail (e.g., Kurosumi and Katayama, 2005).

When discussing Keitai-mail in terms of their characteristics as a communication medium, they are sometimes compared with letters or PC e-mail. While these may seem similar, however, Japanese people feel that they are a different communication medium. Oe (2007) points out that, at the present time, a letter is regarded as formal writing intended to convey the sender's thoughts and messages, PC e-mail is an informal written communication, and Keitai-mail are a convenient written communication medium; therefore, Japanese people use these media differently depending on their purpose of communication. This is why the language of Keitai-mail needs to be analysed as a new genre of communication even though it seems to share similarities with pre-existing media.

\subsection{Emoticons}

The third one is Emoticons. Since Keitai-mail include richer sources of emoticons or special symbols as defaults, people make frequent use of these emoticons and symbols, especially by comparison with their use in other media such as letters, postcards, and PC e-mail (Yamanishi, 2007). In general, people use the emoticons which come already installed in Keitai, but some do create new emoticons from combinations of letters the platform provides. In the latter case, people usually also download new emoticons from Internet sites, or recycle new emoticons received from friends (Ono \& Tokuda, 2005). Because these emoticons and symbols are so easy to use, they often appear in Keitai-mail in order to prevent the text from appearing bland (Yamanishi, 2007).

Kitani (2003) mentions that emoticons are used to add emotional expressions, to create an enjoyable and relaxing communication atmosphere, and to show intimacy, and Yamaguchi and Joh (2000) report that texts with emoticons actually give a different impression from those without them. For instance, young people generally receive a positive impression (cute, interesting, fun), whereas some people feel emoticons are not serious and are even rude (Miyake, 2002). Yasuhara et al. (2009) argue that emoticons entail an image of lack of seriousness and sincerity, so it is not appropriate to use them in business.

From this point of view, emoticons actually function to convey the emotion of the sender. This is because they substitute for facial expression in Keitai-mail communication (Kato, Kato, Kobayashi, \& Yanagisawa, 2007): people can understand their interlocutors' intentions better when emoticons are used (Takahashi, Fukada, \& Akimitsu, 2005). Therefore they play a role in making communication smoother (Uchida, 2004). As discussed previously, people depend heavily on non-verbal cues, particularly facial expressions, in communication in order to understand their interlocutors' intentions and it is very difficult to communicate without such non-verbal cues. Emoticons substitute for these non-verbal cues and therefore they actually support proper understanding of others and smooth communication through Keitai-mail, a written-medium communication 
Moreover, since people can visually understand the message when they see emoticons, these symbols can substitute for a word or phrase written using several Japanese syllables (Hayashi, 2007). At the same time, as Ono and Tokuda (2005) point out, although emoticons carry a certain meaning in themselves, people generally interpret their meaning based on the context in which they are used and in the overall e-mail exchange. Therefore, emoticons are also said to be context-dependent symbols which supportively add an emotion or meaning to content. Emoticon use is an important characteristic of Keitai-mail, so that Keitai-mail without emoticons is sometimes regarded as sloppy (Ono \& Tokuda, 2005) and even induces anger and sadness in interlocutors (Kato et al., 2006b).

One fundamental question relating to emoticons is whether they are pictures or letters. Kimura (2002) investigates this question: her study concludes that people regard emoticons as pictures rather than letters, and that emoticons are used not to replace words written in the five Japanese scripts but to function as supplements or additions. This also can be discussed from the viewpoint suggested by Azuma and Ebner (2008), namely that such emoticons can function as a universal language among speakers of different languages with a certain degree of success. Their report indicates that interpretation of emoticons is not restricted by language and that emoticons therefore can be viewed as not belonging to the scripts of any particular language.

\section{Method}

This study analyses the questionnaire collected from 60 Japanese young people (aged 18 to 30, ratio of male to female is 1:1. i.e, 30 male participants and 30 female participants) during May 2009 to January 2010, (with 43,295 Keitai-mail for communication purposes). The questionnaire aimed to discover how participants create texts on Keitai: for example, how they use abbreviations, Kanji, emoticons, or special expressions in Keitai-mail. In addition, users psychology how they deal with Keitai-mail were investigated.

Each section consisted of an exchange of questions and answers, scale evaluation questions, multiple-choice questions (some questions in 'all that apply' style), and open-ended questions. Most questions firstly asked closed questions in order to reveal what participants think of matters related to Keitai and language use. Closed questions result in answers which reflect respondents' natural perceptions. Next, participants answered open-ended questions asking why they answered the closed questions in the way they did. This was a self-investigation process intended to clarify their actions and perceptions more concretely, which further elucidated conscious and unconscious use of language or expressions in Keitai-mail through concurrent analysis of the discourse from their Keitai. In addition to these questions, other types of open-ended questions explored the original source of their language use.

\section{Result}

This section discusses how young people perceive Keitai-mail communication based on their answers to the questionnaire. Firstly, Figure 1 illustrates the extent to which they include emoticons in Keitai-mail ("Do you frequently use emoticons?") and shows that participants, particularly female participants, use emoticons frequently in their texts.

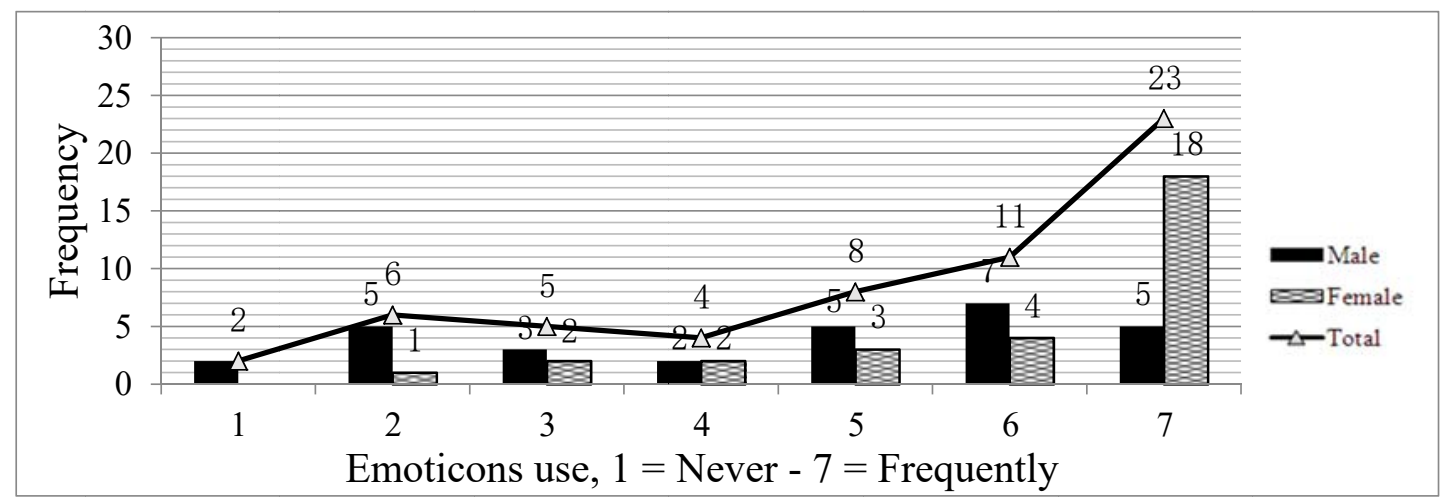

Figure 1. Frequency of use of emoticons

The questionnaire asks why participants use emoticons and with what intention; answers can be separated into several categories. The first reason is to add some emotional expression. It is difficult to convey these emotions through language alone, and emoticons (as their name shows) are effective devices for displaying emotion or 
nuances to the recipient of the message through a visually transparent method. In other words, emoticons are used as a substitute for the facial expressions used when communicating in person. In addition, some respondents mentioned that the number of emoticons reflects the strength of their feelings: if they use two or more emoticons at a time, this means they are expressing strong feeling.

The other major reason is to change the impression of the text to make it soft, cheerful and cute-looking. The application of emoticons gives an overall atmosphere which influences the whole impression of a Keitai-mail. This means emoticons have a function beyond conveying the feeling or message each emoticon indicates; their role is greater than their original meaning.

The questionnaire also shows that the use of emoticons is a reflection of friendliness and closeness. At the same time, not to use emoticons gives an impression of coldness and lack of motivation in communication; some people feel that to receive Keitai-mail without emoticons makes them feel as though the sender hates them. Therefore, emoticons also function to control the relationship between senders and recipients.

In addition to emoticons, other decorative symbols and expressions are also used in the same way, and these too reflect clear intentions. In summary, emoticons and other decorative symbols function to convey feelings, to change the impression of the whole text, and to control the distance between interlocutors. Therefore, these symbols are important communication devices in Keitai-mail which go beyond language, and people intentionally use them for effective communication in maximizing information in Keitai-mail.

To illuminate further the aspect of Keitai-mailing in relation to interlocutors, the questionnaire also asked about participants' intentions in choosing the register used based on who their interlocutors are. Figure 2 shows answers to this question and provides evidence that participants do change their expressions in Keitai-mail in relation to different interlocutors, as can be seen from the high average score of 5.8 (Male=5.71, Female=5.90).

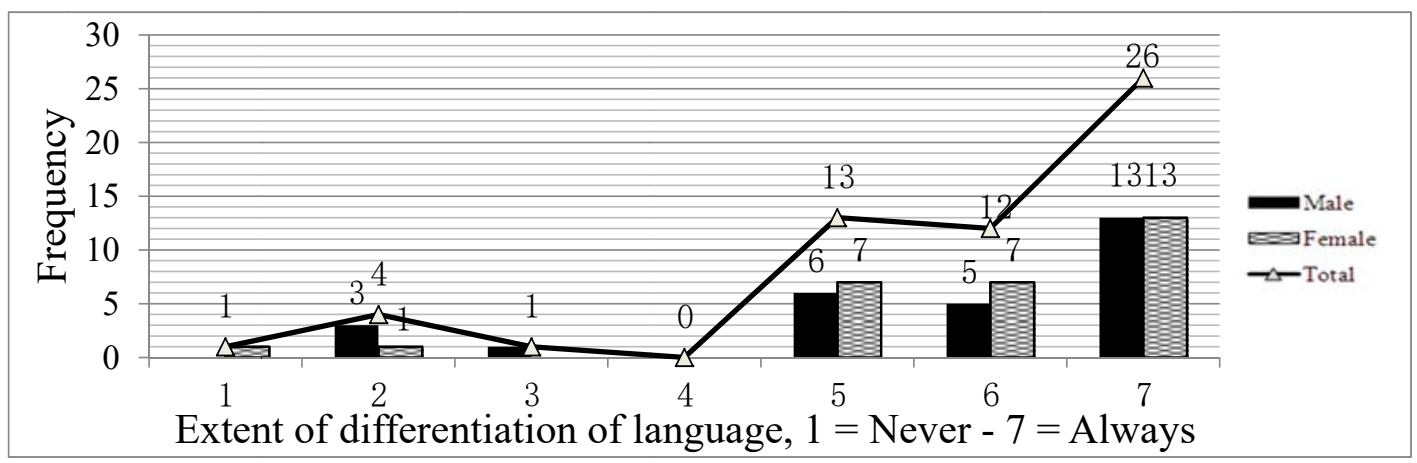

Figure 2. Extent of differentiation of language in Keitai-mail based on interlocutor

Note. This figure is from Question "Do you change the language or expressions of your e-mail texts based who will receive them?"

This can seen in Keitai-mail which are on the same topic but are sent to different interlocutors. The following CA (in terms of underlying psychological analysis) is a sequence of Keitai-mail in which the sender (female) informs a series of different recipients about a farewell party and asks whether the interlocutor(s) can attend it (the texts are presented in chronological order).

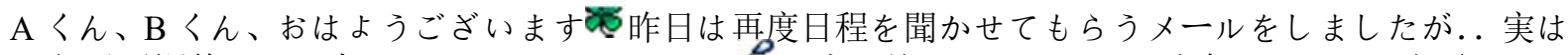
$\mathrm{C}$ 組が再調整しても来䛱なことになりました゚、4人一緒にできなくて、残念だけど、予定通り、8 日（金）でいきたいと思いますきお二人とも大丈夫かな？当日までに、何かあれば、遠慮なく私まで 連絡下さい@⿴囗大

[A-kun", B-kun, Good morning I sent a mail for reconfirmation of schedule. . C couple cannot make it even if we try to have another adjustmente $\mathrm{I}$ am sorry that all four of you cannot meet together, but we'd like to have [the farewell party] on the 8th (Friday) as per the original plan ${ }^{\text {B }}$ Both of you can make it? If you have any questions before the meeting day, please don't hesitate to contact me

*kun: title for males in relatively close relationship ${ }^{* *} \mathrm{Z}$ is anonymous form of sender's name

D一おはょう四昨日は E ちゃんと会ってたらしいね悍ふふい情報ゲットしちゃった（笑）壮行会なんだ

けど、結局空き日程変わらずだったので、8 日で決行したいと思います!!! ちなみに参加者は $\mathrm{F}$ 組の 
$\mathrm{G} く ん \& \mathrm{H}$ んん当日までに色紙とかできたらいいねーの6日の夜に買い物できたらべストだわ一古 Jに一緒に選んでもらうことになるかもだけど...(..)

[D- Good morning(S)You met E yesterday, didn't youl' everyone's schedule is not changeable, we have it on the 8th!!! Participants will be G-kun and H kun in F group It would be good if we can make a card by the farewell party ${ }^{2}$ think it is the best if we can go shopping at night on the 6 th $^{{ }^{\circ}+}$ I will ask $\mathrm{J}$ to choose together. . (...) ]

$\mathrm{K}$ オ八ー防今日の $\triangle \triangle$ 飲み来る？８日の○○壮行会来れる?

[K, Gdmornin-

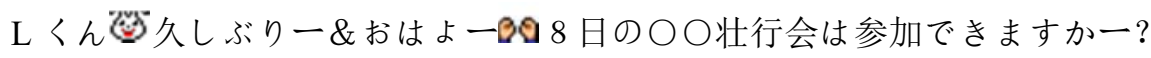

[L-kun Long time no see-\& Goodmornin'一 C Can you make time for $\bigcirc \bigcirc$ on the 8 th -? ]

$\mathrm{M}$ ちゃん志久しぶりー\&らおはょ一の 8 日の○○壮行会は参加できますか一?

[M-chan 2 Long time no see-\&Goodmornin'一 Can you make time for $\bigcirc \bigcirc$ on the 8th -?]

*chan: title for females in relatively close relationship

$\mathrm{N}$ くん罗おはよ一B日８日の○○壮行会は参加できますか？たしかバイトだったよねメ

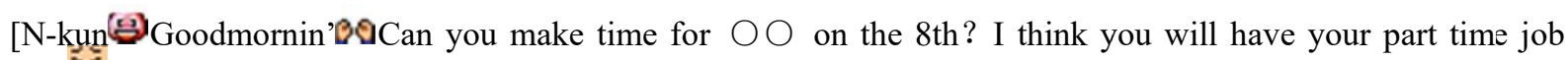
then $\approx$ ]

In this exchange, the first two mails are long, followed by three short texts. This means the mails she first sent required consideration as well as actual input effort. Therefore, it can be seen that she likes to create those texts which she needs to spend time on creating first. In addition, the first mail and the second mail are different in nature: the first one is composed to sound polite, with more formal language, whereas the second one is full of casual expressions. This provides further evidence that she prioritised sending the text which needed careful planning to a person from whom she has relatively more distance. Moreover, the Emoji which exhibit a smile are differently used: the first one has 9 and the second $\mathrm{O}$. Compared to the first one, the second one implies a clearer emotion of happiness. In the Japanese sense, showing clear emotions indicates a relatively close relationship. She thus has a closer relationship with the interlocutor of the second mail than the first, and her use of emoticons, even though subtly, reflects the conservative nature of language use to the person who is less intimate. This usage of Emoji can be also seen in the fifth mail that also includes the clearer smile Emoji ().

Comparing the morning greetings used in the five texts, the first uses the most formal one おはようございま す/o ha yo u go za i ma su/; the second has a short version おはよう/o ha yo u/; the third オハー is written in Katakana with a long vowel symbol, the most distinctive of the five; the last three Keitai-mail use おはよー, basically the same as the second one, but with the last vowel j changed to a long vowel symbol —. This indicates an interesting motive in Keitai-mail composition, as follows. The first mail is the most careful composition to the least intimate of the target senders. Then the content becomes casual. However, interestingly, the third is the most casual and then the sender uses a bit of formal writing. This can be interpreted as that, firstly the last four Keitai-mail have the same pattern (styles), and in a situation when she sends texts with a similar pattern, she chooses the closest friend as her first interlocutor who sends a message because of its ease of text creation of intimacy, then she writes a little more formal Keitai-mail to those who are less close. The degree of closeness is also reflected in how they address interlocutors such as by title or just by name.

This example shows that people change their register of language and emoticon use (styles, particularly body-language and phonological aspects (LP)), as well as the topic (representation of social events) included in a single mail, based very clearly on who their interlocutor is, even when sending Keitai-mail with similar content or intention. The questionnaire results show that people use different language in the context of the following major relationships:

- Seniors/Same age and juniors

- Men/Women

- Boyfriend/Girlfriend

- Family

- Close friends/others

As is the case with other forms of communication, people use Keigo when communicating with their seniors. They also use fewer or no emoticons. This shows that emoticons are still regarded as informal or impolite 
language and as not proper in communication requiring polite expression. Some thought that the register used to send a message to seniors using polite language is similar to that used in communication by PC. This indicates that although PC e-mail and Keitai-mail both use electronic media, the perception of each type of communication and message creation is different, showing that Keitai-mail have a style of their own.

The second difference, that between men and women, is also interesting. Both male and female participants indicated that they put more thought into the content of their messages when sending to females rather than males, which is reflected in the different use of emoticons as well as in the language used itself. Thirdly, for boyfriends/girlfriends, people tend to create decorated mail, particularly with heart marks or emoticons indicating love; the content itself also reflects their closeness.

For the fourth point, people create very frank and plain messages for their family members, which for the most part include few or no emoticons, and this phenomenon can be explained through the fifth difference in messaging to close friends or others. Generally, people use emoticons and other methods of decoration in creating messages to their friends, and they tend not to do so when they send a message to those who are not so familiar to them. This can be seen in messages to their seniors, who are usually less close than their friends. At the same time, interestingly, people tend to create simple mails when sending to those with whom they have a close relationship, in particular family members. Therefore, a particularly close relationship is regarded as a relationship in which people do not need to include decorative symbols in Keitai-mail and they create a very simple message in these cases.

Table 1. Replying practice of participants

\begin{tabular}{|c|c|c|c|c|c|c|}
\hline \multirow[t]{2}{*}{ Item } & \multicolumn{2}{|c|}{ Male } & \multicolumn{2}{|c|}{ Female } & \multicolumn{2}{|c|}{ Total } \\
\hline & $\mathrm{F}$ & $\mathrm{S}$ & $\mathrm{F}$ & $\mathrm{S}$ & $\mathrm{F}$ & S \\
\hline $\begin{array}{l}\text { 1. I reply to e-mail immediately all the time except in extreme } \\
\text { special circumstances. }\end{array}$ & 3 & 0 & 2 & 0 & 5 & 0 \\
\hline 2. I reply to e-mail immediately all the time if I am free. & 6 & 0 & 9 & 0 & 15 & 0 \\
\hline $\begin{array}{l}\text { 3. I choose whether I reply immediately or not based on senders or } \\
\text { content of e-mail. }\end{array}$ & 16 & 0 & 13 & 0 & 29 & 0 \\
\hline a. I reply immediately if the content is very important. & 15 & 0 & 12 & 0 & 27 & 0 \\
\hline b. I reply immediately if the content of e-mail is easy to reply. & 8 & 0 & 9 & 0 & 17 & 0 \\
\hline c. I reply immediately if I receive e-mail from my close friends. & 6 & 0 & 4 & 0 & 10 & 0 \\
\hline $\begin{array}{l}\text { d. I reply immediately if I receive e-mail from seniors or my boss, } \\
\text { those who have a higher position in society. }\end{array}$ & 10 & 0 & 7 & 0 & 17 & 0 \\
\hline e. I reply immediately if I receive e-mail from my family. & 2 & 0 & 3 & 0 & 5 & 0 \\
\hline $\begin{array}{l}\text { 4. I generally reply immediately not based on the content or sender, } \\
\text { but based on how easy the content of the e-mail is to reply to. }\end{array}$ & 1 & 0 & 9 & 0 & 10 & 0 \\
\hline $\begin{array}{l}\text { 5. I do not worry about anything, and just decide whether I reply or } \\
\text { not based on my feelings or the situation. }\end{array}$ & 3 & 0 & 2 & 0 & 5 & 0 \\
\hline
\end{tabular}

Abbreviations. F: Frequently; S: Sometimes

On this point, whether someone likes their interlocutor or not also influences emoticon use and content. If they dislike an interlocutor, they create simple, plain messages which indicate their unwillingness to communicate as well as their tiredness in texting (in the expectation that the interlocutor will intuit their dislike through the text). This reflects unwillingness to take extra effort in creating the message as well exemplifying the finding that Keitai-mail without emoticons give an impression of coldness or anger to recipients.

Analysing the different patterns of message creation and the sample texts shows that people use expressions differently in texts, particularly emoticons and other methods of decoration, based on who their interlocutors are, and that this intentional use is a reflection of the relationship as well as even acting to control the relationship. Emoticons and other decorative symbols are thus used as distance and politeness markers in texts and play an extralinguistic role in controlling the relationship with interlocutors. 
On another aspect of underlying motives in Keitai-communication, Table 1 illustrates how participants reply when they receive Keitai-mail through their answers to Question "How do you respond when you receive e-mail? Please choose one of the statements from 1 to 6 which shows the most similarity to your opinion. If you choose 3 , please further choose from a to $\mathrm{f}^{\prime}$.

No general tendency can easily be determined in this result, but the timing of a reply is related to the following three elements: whether or not participants are free to do so at that moment, senders and content (important or easy). Most of the participants are influenced by at least one of these elements, and this can be said to be one of the basic underlying motivations in replying to Keitai-mail, or a perception of the conversational nature of Keitai-mail related to turn-taking.

To further explore their perceptions of Keitai-mail use, Table 2 illustrates what kinds of perceptions participants have of Keitai-mail communication (Question "What kind of impression do you have of communication through mobile phone e-mail? (Check all that apply)

Table 2. Participants' impressions of Keitai-mail

\begin{tabular}{|c|c|c|c|c|c|c|}
\hline \multirow[t]{2}{*}{ Item } & \multicolumn{2}{|c|}{ Male } & \multicolumn{2}{|c|}{ Female } & \multicolumn{2}{|c|}{ Total } \\
\hline & A & $\mathrm{P}$ & A & $\mathrm{P}$ & A & $\mathrm{P}$ \\
\hline 1. Communication by mobile phone e-mail is easy. & 18 & 0 & 20 & 0 & 38 & 0 \\
\hline 2. I can reply carefully because I can spend time to do so. & 14 & 0 & 10 & 0 & 24 & 0 \\
\hline 3. Mobile phone e-mail is convenient for small talk. & 23 & 0 & 25 & 0 & 48 & 0 \\
\hline $\begin{array}{l}\text { 4. I can say what I tend to hesitate to say in person or by a phone } \\
\text { call (such as to apologise) through mobile phone e-mail. }\end{array}$ & 7 & 1 & 10 & 0 & 17 & 1 \\
\hline $\begin{array}{l}\text { 5. I find it easier to ask something by e-mail than face-to-face or in } \\
\text { a phone call. }\end{array}$ & 6 & 1 & 3 & 0 & 9 & 1 \\
\hline 6. I can communicate more with people through e-mail. & 5 & 0 & 14 & 0 & 19 & 0 \\
\hline $\begin{array}{l}\text { 7. I feel that the relationship with close friends is weak since we } \\
\text { can communicate by mobile phone e-mail. }\end{array}$ & 3 & 0 & 4 & 0 & 7 & 0 \\
\hline $\begin{array}{l}\text { 8. I tend to be emotional when communicating by mobile phone } \\
\text { e-mail more than in person or in a phone call. }\end{array}$ & 0 & 0 & 2 & 1 & 2 & 1 \\
\hline $\begin{array}{l}\text { 9. I feel anxiety or irritation when the reply does not come back } \\
\text { immediately. }\end{array}$ & 9 & 0 & 10 & 1 & 19 & 1 \\
\hline 10. I feel sorry if I don't reply immediately when I receive e-mail. & 8 & 1 & 9 & 2 & 17 & 3 \\
\hline
\end{tabular}

Abbreviations. F: Frequently; S: Sometimes

Many participants feel that Keitai-mail communication is easy (Item 1) and convenient, particularly for small talk (Item 3). In addition, some feel that Keitai-mail enable them to communicate better (Item 6). At the same time, this type of communication causes concern for some (Items 9 and 10).

Many perceive Keitai-mail as an easy communication tool, which at the same time enables them to convey messages which sometimes they hesitate to say in person (Items 4 and 5), so that Keitai-mail are used for more serious messages. On this point, Figure 3 shows what sort of important messages participants send via Keitai-mail (Question “To what extent do you speak of important matters in mobile e-mail?”)

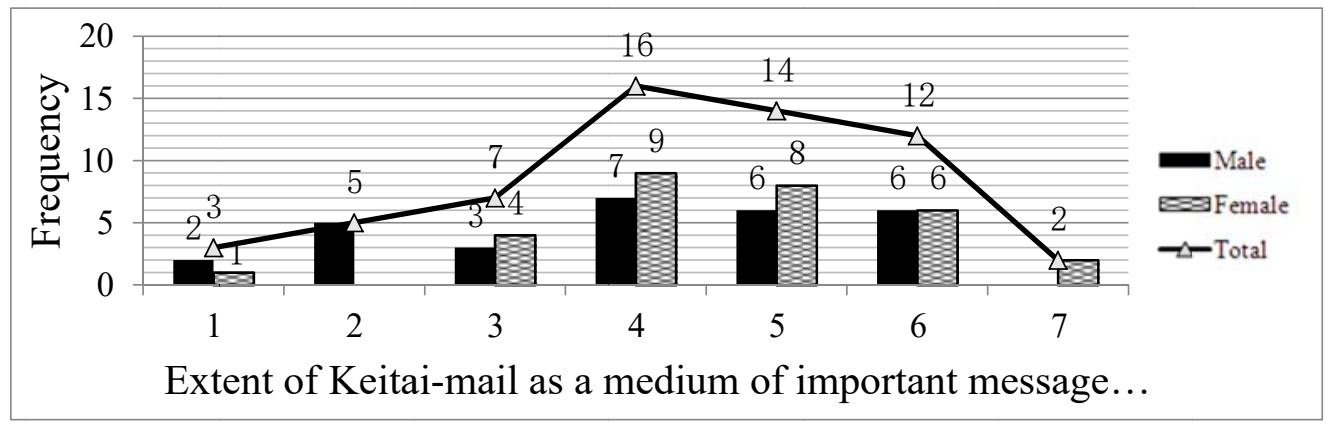

Figure 3. Keitai-mail as an acceptable medium for important messages

This chart indicates that even though Keitai-mail are not suitable for saying everything, many of the participants use them to send relatively important messages. An open question (Question, When you use or don't use 
Keitai-mail) also gives a perspective on this point: as the figure shows, the level of important messages they send varies, but one general trend seen in the answers is that if messages are important, they prefer to use a phone call rather than Keitai-mail. Moreover, Keitai-mail are sometimes used as a second follow-up choice when interlocutors do not take their call. Keitai-mail have thus not yet overtaken the position of a phone call but instead extend the communication since they send/receive messages which are not so significant and would not have been exchanged via previous media.

The reason participants use Keitai-mail and phone calls in this way is that Keitai-mail are useful in easy and convenient communication such as arranging a meeting or in casual communication. At the same time, people also have a perception of Keitai-mail as easy and convenient, so that messaging via Keitai-mail is not regarded as serious or urgent. Sometimes use of Keitai-mail for important matters can be regarded as rude. Therefore, people avoid using Keitai-mail for highly serious and significant communication in order to notify their interlocutors that the communication is intended to be serious. On the other hand, they utilise the convenience of Keitai-mail for their part of the communication and this is also preferred over a phone call in non-serious communication.

To seek an overall perception of Keitai-mail as a medium, Question asks "Which do you think communication via e-mail is more similar to: communication by letters, or a phone call?" Figure 4 represents answers.

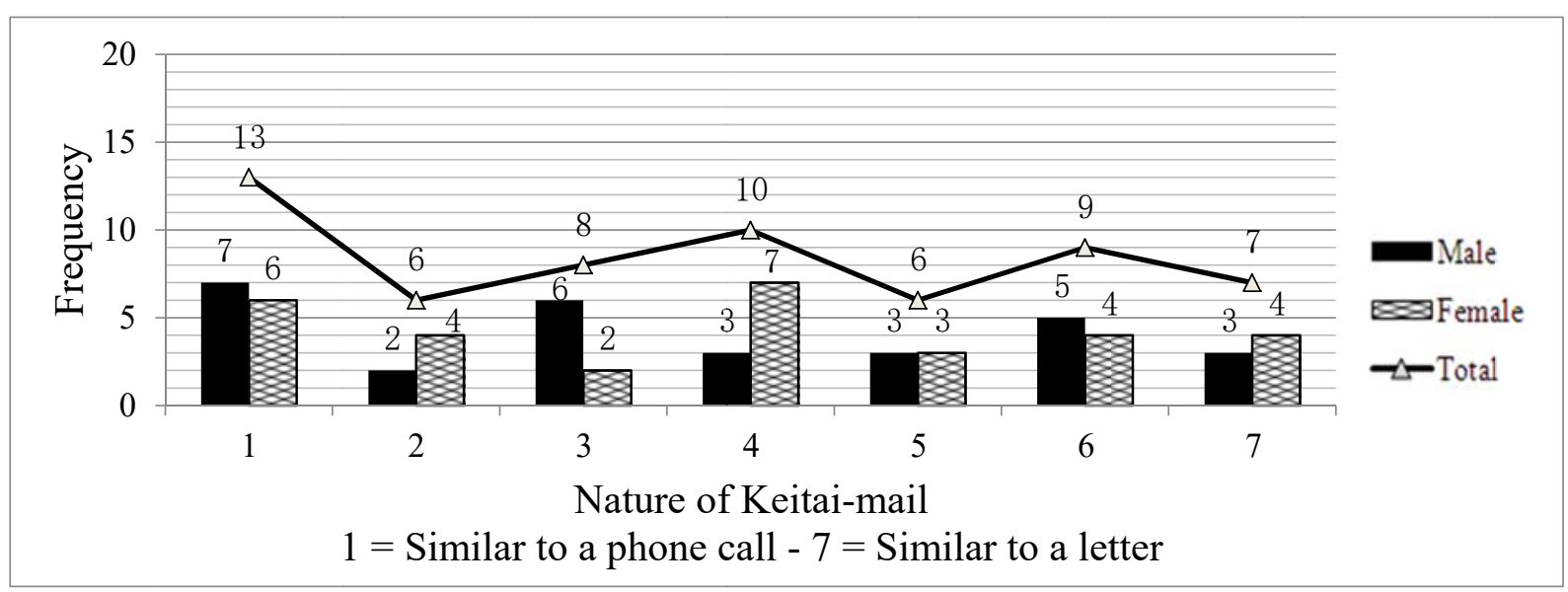

Figure 4. The nature of Keitai-mail

Note. Average: Male $=3.67$, Female $=3.83$, Total $=3.76$

As the average scores show, participants tended to perceive the nature of this communication as similar to a phone call, but the answers are distributed and the perception depends on each person's opinion. Participants who feel Keitai-mail are relatively like a letter point out that both Keitai-mail and letters are written communications and use moji. On the other hand, those who perceive Keitai-mail as relatively like a phone call focus on the seamless property of communication they offer. These perceptions reflect the characteristics of Keitai-mail and a difference in their focus may account for the difference in their evaluations.

One particular opinion on this question illuminates the difference between paper-based letters and Keitai-mail. Technically, the difference between these two is that one is electronic-based and the other is not, but some respondents mention that letters are 'heart-filled' communications which are very much considerate of the recipients, whereas Keitai-mail are too easy in comparison.

This indicates that even Japanese young people hold a special perception of paper-based letters and that Keitai-mail, even though referred to as electronic-based 'letters', have not achieved the position of being considered a suitable medium for deep communication.

To summarise this section introduces the answers on the questionnaire to the open question of how participants feel about Keitai-mail communication. Basically, the general trends in their answers show the same tendency discussed above: they point out the convenience of Keitai-mail as an easy communication medium. Respondents also mention that they sometimes feel that Keitai-mail have become a chore in terms of input as well as expectations for a quick response in certain situations. The fact that a cell phone is a portable communication device gives a sense of connection over physical distance, but at the same time, they also feel they are always open to interruption in comparison to the time they spend without Keitai-mail. Another opinion is that 
connection via Keitai-mail decreases real connection with people and that this tendency will become more apparent in the near future. Keitai-mail therefore have a complicated influence on communication among Japanese people and these properties of Keitai-mail call for particular communication strategies for effective communication.

\section{Discussion}

The data and analysis indicate the following characteristics related to psychological factors as underlying motivations in language use and Keitai-mail communication.

- Keitai-mail are seen as easy communications using a casual mode.

- Emoticons are actively used as a reflection of senders' emotions directly and indirectly. However, the emoticons frequently used show a pattern: senders prefer to use only a small set of emoticons for most Keitai-mail communication.

- The use of emoticons induces feelings based on the relationship with the interlocutor, which functions to control distance with them as well (one of the psychological aspects of emoticon use beyond conveying merely their simple surface meaning).

- People have different perspectives on the timing of replies (turn-taking) - some expect an immediate reply and others do not.

- The type of message young people regard as appropriate for Keitai-mail is basically more limited than the messages they would convey by a phone call.

In analysing emotion in the creation of Keitai-mail, emoticons are a major source of information because of their function of conveying extra-textual emotional messages to recipients. This can be seen as a substitute for facial expression in Keitai-mail as Kato et al. (2007) suggest. The discussion below concludes that, in line with Uchida (2004), emoticons make communication smoother through the function introduced by Tachikawa (2005), namely that of improving the clarity of what senders want to convey. In other words, as an extra-textual message conveyer, the application of emoticons used as a substitute for facial expressions or body language is a general style of Keitai-mail.

In general, Keitai-mail are used for casual communication which mainly occurs within a relaxed and intimate relationship. This is the basic psychological foundation of Keitai-mail communication, and language and exchanges are chosen accordingly.

As has also been reported in earlier studies (e.g., Nishimura, 2003; Tachikawa, 2005), almost all sentences in the Keitai-mail collected for this study conclude with emoticons instead of the formal Japanese full stop '。'. In comparison with the use of emoticons as word replacements (which mainly occurs in the middle of sentences) shown in the previous section, the use of emoticons to represent emotions accounts for most occurrences. This can be interpreted further to mean that among several choices of location where emoticons are added, their insertion at the end of sentences indicates that they are regarded as having a supplementary function, representing emotions only after a message has first been expressed in language itself. At first glance, this reflects the situation discussed by Ono \& Tokuda (2005), namely that emoticons carry a positive image for young people, and this explains the frequent use of emoticons by young people revealed by the present study's questionnaire data.

Keitai platforms contain large sets of pre-installed emoticons (particularly Emoji), but people tend to use only a small subset of these frequently in composition. The data show that they prefer to use emoticons which involve a more abstract picture rather than actual pictures of faces. For example, a splash of sweat $\left({ }^{\circ} \otimes\right)$ and shining $\left(\hat{\rho}_{+}\right)$ are preferred: the former indicates something negative, the latter something positive. Compared to other Emoji which actually show a face (e.g., (3), these Emoji can express a wider range of feeling, so they are easily applied in texts with the expectation of less misinterpretation. In other words, in CA terms, this can also be seen as a conversational technique to fulfil conversational expectations which interlocutors will have, as opposed to the case of violation of adjacency pairs discussed in the last section. Naturally, therefore, they are often used in Keitai-mail.

The nature of Keitai-mail as context-based communication is seen in the use of language itself as discussed in the previous section, but the underlying motives investigated in this study also provide additional evidence to support this property. As the example show, people sometimes write messages about the same thing in a different manner based on their relationship with interlocutors, e.g., they change register, using Keigo instead of casual language with emoticons. 
Context-based communication relates to the relationship between exchange partners. Riviere and Licoppe (2005) categorise types of interlocutors into three groups: 1) family members and close friends, 2) friends of less frequent contact or who are less close, and 3) acquaintances. These relationships decide the register of language. In terms of linguistic means, Keitai-mail also fit this categorisation; emoticon uses, on the other hand, do not. Basically, the closer the interlocutors are, the more people tend to use emoticons. In addition, Keitai-mail from close friends without emoticons makes the recipients think the sender is displaying distance, coldness, lack of interest or even anger, as suggested by Ono and Tokuda (2005). As a result of this lack, recipients therefore also feel anger or sadness (Kato et al., 2006b). In other words, evaluation of the desirable/non-desirable in composition depends on the interlocutors, not solely on the property of the medium itself.

The texts as reflections of senders' psychological states are further discussed by Kadono and Hishimoto (2009) as ultimately showing that the pattern of composition reveals what kinds of emotions they had in creating Keitai-mail. Therefore, the phenomenon above can be discussed as showing that the sense which enables people to associate interlocutors' underlying motivations and thoughts in texts will then in turn stimulate some feelings in the recipients. In that sense, the use of emoticons in order not to induce negative emotions can be seen as negative politeness strategies (Miyake, 2003b), in the same way as Miyake found in 2003 that Japanese young people internalise the conventions of the Japanese culture which suggest that people should avoid causing negative feelings by inappropriate language uses.

This phenomenon is also described as people using emoticons as a device to enhance a relationship since they know both the positive impression given by Keitai-mail with emoticons (see, e.g., Miyake's 2002 report) and the negative effect of a lack of emoticons on a feeling of closeness. They can control the relationship, or at least give an inference of the relationship they have with their interlocutors, through the extent to which they use emoticons. This is one reason Keitai-mail are highly context-dependent. Senders need to be aware of the amount of emoticon use appropriate for exchanges.

One interesting exception to the linear relationship between closeness and number of emoticons found in the corpus is Keitai-mail sent to family members, which are quite flat with few or no emoticons or even punctuation. In these cases, senders do not use emoticons where they do not have to. This indicates a feeling of tiredness in using emoticons requiring extra input - otherwise they would be willing to use them in a relationship without consideration for language use (in a relaxed state of mind). This can be further interpreted as showing that emoticons are deliberately used in non-family messages to increase the effectiveness of communication in other situations where it is perceived as appropriate.

As for the use of small moji in irregular places, Gottlieb (2011) notes that this is done with the intention of adding cuteness to the message. All this is a reflection of style as a representation of identity: writers apply an image or description to characterise the personality they have or even that they want to have. Some of the participants in the present study agreed and actively applied this form, while others disliked it when others did this and expressed their frustration about having to read such expressions. This latter shows that those who do not accept such expressions interpret the representation of identity in a negative way; evaluation of to what extent the expression is desirable is important in order to convey the message that the senders intend.

The phenomena above indicate the nature of the literacy practice of Keitai-mail as a highly context-based practice, as is also seen in the answers on the questionnaire that indicate that people are highly sensitive in their language use based on who their interlocutor is. This reflects how they handle a message based on who their interlocutor is in order to communicate appropriately.

The mode people feel Keitai-mail to be also relates to their Keitai-mail practice. Some scholars (e.g., Amasa et al., 2004; Fujimoto, 2006; Hayashi, 2007) argue for the semi-synchronicity of Keitai-mail communication as Keitai-mail are expected to be replied to as soon as possible. In the data on actual practice disclosed, the reason for non-immediate reply was found to vary widely depending on the person. However, there would be consensus in Japan that failure to send a quick reply to a Keitai-mail is excusable if there is a good reason for it. If interlocutors do not accept the reasons given, the practice would be regarded as rude (as reported by Fujimoto (2006)) and in these cases Keitai-mail become sources of burden in communication between the pair as a result. This semi-synchronicity influences how people think and behave in their Keitai-mail practice, and this is an underlying motive in how they compose their message as a reflection of their conscious/unconscious thoughts about what is appropriate based on this timeframe, e.g., phrases of apology for the delay should be stated.

Moreover, as Kato et al. (2006b) discuss, even though Keitai-mail can be regarded as synchronic rather than asynchronic communication, people expect messages not to be too abrupt, otherwise they receive a negative impression of the message and of their interlocutor. In this regard, the data show that the average length of 
Keitai-mail is actually 40 moji, more than could be expected in abrupt messages, and half of them consist of two or more genres. This reflects these expectations.

It can be also shown that, even though both phone calls and e-mails using Keitai are context-based, people tend not to use Keitai-mail when conveying important matters, preferring to make a phone call instead. This is a reflection of the complex nature of Keitai-mail, in which the perception of mode and the expectation of content are different. In other words, the discourse of a phone call can be adjusted immediately since it is synchronous, but it is more difficult to do this with Keitai-mail because of their nature, and people tend to avoid Keitai-mail exchanges involving some sensitivity in order not to convey an unintended message to interlocutors.

To discuss the perspective of turn-taking (CA): Amasa et al. (2004) report that Keitai-mail have the characteristic of demanding an immediate reply, or at least the expectation of an immediate reply, since as Fujimoto (2006) points out those who exchange Keitai-mail are carrying their Keitai on their persons. The turn of utterances is therefore only controlled by the current sender. In other words, it is what Amasa et al. (2004) call 'sender-centred communication'. This means that Keitai-mail allow users to create a composition which has a certain conclusiveness of discourse. Therefore, unlike other seamless communications such as chatting or a phone call, turn-taking by current recipients (as mentioned by Worffitt, 2005) does not occur in Keitai-mail. This means that, although it is possible that both users could send and input Keitai-mail at the same time, the discourse of each sender will be concluded without interference from the recipient in terms of the level of text composition. In other words, using a CA approach, both speakers have the initiative in turn taking and in constructing the architecture of interaction. This conclusiveness of composition in (potentially) immediate exchanges is a particular property of Keitai-mail and this mode possesses various specific characteristics which distinguish it from other pre-existing media.

As the reflection of sound information in Keitai-mail text shows, the characteristics of Keitai-mail are heavily influenced by oral communication. Tsuji (2003) describes this as consummatory characteristics, and the emoticons of Keitai-mail derived through the data obtained in this study provide quantitative evidence for this. For example, the average length of Keitai-mail is at best 40 moji, which generally contains few genres (at best, four in a text) along with several emoticons and other symbols. This means the content itself is as short as turn-taking exchanges in oral communication.

This communication style is regarded as 'intentional' to a certain extent, but it might be more appropriate to say that the language and communication appearing in Keitai-mail are the result of 'natural' behaviour which basically does not require special attention to the form of language and composition. However, as noted, since the main partners in the interaction are usually known and close to each other, they also pay a certain amount of attention to creating interesting texts. These efforts go beyond grammatical correctness or appropriateness of composition (e.g., the correct use of Keigo, or of appropriate particles). The opinions from this study's data reflect this tendency.

Moreover, the 'uniqueness' is used in a limited and systematic manner. Users' main motivation is to create an interesting message without interfering with effective communication, in terms of their burden of composition as well as of the interlocutor's understanding.

Barton (2007) refers to the longevity of written language and this property of written language helps to retain spoken and non-verbal language in a certain systematic manner. A fundamental underlying motivation is effective communication: how to maximise the message conveyed, including emotion and atmosphere. A traditional view of maxims of communication (Grice, 1975) focuses on the quantitative, the qualitative, the relational and the preciseness of utterances. Keitai-mail seem to include many violations in terms of language use itself, since there are many ungrammatical and extra components if we consider only standard Japanese writing practices. However, these additional components function as powerful conveyers of meaning which add non-verbal information. A difficult aspect of Keitai-mail communication is that the appropriateness of content is context-dependent, in order to be effective between certain people acting under certain communication norms. At the same time, visualisation can cause some confusion for recipients when the imagined picture and the picture displayed do not correspond (Iseki, 2010). An example case is:

$$
\begin{aligned}
& \text { M: }= \\
& \text { F:えええ゚゚なんでその絵文字? } \\
& \text { [F: Oops } \approx \text { Why do you use this Emoji? } \Theta^{\circ} \text { ] }
\end{aligned}
$$

This very short exchange (in CA terms) clearly shows that the second speaker was upset because the message of the Emoji was different from the message she expected. In other words, the emoticon causes a violation of 
adjacency pairs, which further results in a decrease in mutual intelligibility. Thus, emoticons entail a fundamental risk of miscommunication which cannot be dealt with by any kind of standardisation.

Therefore, Keitai-mail are a highly context-dependent literacy practice, and any 'uniqueness' of language which characterises an element of style therein is simply a natural application of language to suit this particular communication mode. Naturalness of communication gives rise to unformulated aspects which involve some uncertainty as to their appropriateness. In that sense, non-conventional aspects of language use in Keitai-mail (e.g., irregular use of the five scripts) are a natural part of language use for Japanese people, but are also not formalised or standardised since expectations of conformity with the official conventions are too widespread.

\section{Conclusion}

To sum up, Keitai-mail are short: the average length is 40 letters. The average number of genres contained in each mail is 2.4. The data show that Keitai-mail are longer texts than the very truncated messages which occur in the totally seamless text communication of Internet chat. The average number of emoticons used, 3 , corresponds to the average number of genres found when we consider that almost all sentences in Keitai-mail are concluded by emoticons. In addition to emoticon use, Keitai-mail include several types of LP such as conversions of script types, irregular size of some scripts, and use of long vowel syllables. Basically, simple applications of LP are chosen and LP follows standard Japanese linguistic conventions, as can be seen in the pattern of vowels substituted in LP. From these points, Keitai-mail can be seen as brief but reasonably complete messages, and the LP used, although they permit creativity in expression, are not too different from standard language forms, meaning that messages can be successfully understood, i.e., they fulfil CA's criterion of mutual intelligibility.

Moreover, Keitai-mail are generally regarded as a casual and easy communication method which is suitable for the exchange of less significant matters than is the case with other media such as phone calls or letters. At the same time, the norms and uses of Keitai-mail practice vary from person to person and situation to situation and appropriateness of communication is differentially defined (evaluated) between different people, so that Keitai-mail are therefore very much context-dependent communication. For instance, the use of emoticons or irregular small letters is regarded as an interesting decorative touch which increases cuteness and creates a feeling of warm communication by some participants, but others prefer not to use them because they think that significant irregularity in language use projects an image of immaturity or even stupidity. Styles lead to a certain presentation of identity. In either case, people try to realise effective communication with particular interlocutors using the techniques available to them; in particular, LP and extra-textual components (including phonological and body language aspects involved in Keitai-mail) are actively applied and used as essential conveyors of emotion and atmosphere in the same way as facial expressions are used when talking in person. The lack of them results in sending a negative message to interlocutors. Therefore, Keitai-mail creation involves more than the level of fulfilment of the mutual intelligibility requirement of just understanding the meaning of a message expressed in language alone.

As a further study, an extensive survey with larger participants will illustrate a general, rooted motivation of communication practices accurately; moreover, an interview will also be used to enhance to see the details of users' communication norms. Multidiciplinary approaches will approach the complex mechanism of human communication even step by step.

\section{Acknowledgments}

This paper is based on my Ph.D. dissertation, and I would like to show my appreciation to Emeritus Professor Nanette Gottlieb Dr. Yuriko Nagata and Dr. Michael Harrington. In addition, I would like to extend my thanks to Emeritus Professor Nanette Gottlieb, the University of Queensland, for proofreading this work. Moreover, this research project was supported by several scholarships and a research grant: The University of Queensland, the Faculty of Arts International Scholarship. Nanette Gottlieb's Australian Professorial Fellowship, funded by the Australian Research Council. Tokyo Foundation.

\section{References}

Amasa, K., Fujita, K., Makino, K., \& Higa, H. (2004). E-mail addiction among female students and the psychological characteristics of these students (Part2): The comparison of nursing students with university students. Journal of human nursing studies, 3, 43-49

Azuma, J., \& Ebner, M. (2008). A Stylistic Analysis of Graphic Emoticons: Can they be Candidates for a Universal Visual Language of the Future? Proceedings of World Conference on Educational Media, Hypermedia and Telecommunications (ED-Media), 972-977.

Baron, N. S. (2008). Always on: Language in an online and mobile world. New York: Oxford University Press. 
https://doi.org/10.1093/acprof:oso/9780195313055.001.0001

Barton, D. (2007). Literacy: An introduction to the ecology of written language (2nd ed.). Oxford: Blackwell Publishing.

Fujimoto, K. (2006). Considerations for cellular phone communications: Expansion of noncontiguous space and visible inter-personal relationships. Bulletin of the Faculty of Human and Culture Sciences, Sakushin Gakuin University, 4, 1-14.

Gottlieb, N. (2011). Playing with language in E-Japan: Old wine in new bottles. In N. Gottlieb (Ed.), Language in public space in Japan (pp. 71-85). London: Routledge.

Grice, H. P. (1975). Logic and conversation. In P. Cole, \& J. L. Morgan (Eds.), Syntax and semantics (Vol.3: Speech acts). New York: Academic Press.

Hayashi, R. (2007). Industrial design changes and social trends in view of mobile phone history. Sharp Technical Journal, 95, 24-28.

Horasawa, S. (2005). Overlapping communication space among young people: Face-to-face communication and e-mail communication by portable phones. Bulletin of the Faculty of Regional Studies, Gifu University, 17, $1-20$.

Ida, M. (2003). Some mental factors influencing the degree of use of a cellular phone and cellular-phone mail. The Journal of the Department of Literature, Rissho University, 118, A23-A42.

Ikemoto, S., \& Shiomi, M. (2006). A study on mobile phone and email as communication tools among young people. Bulletin of Junsei Junior College, 35, 173-180.

Iseki, R. (2010). Is the situation model a picture or a proposition? In Y. Hakoda, T. Tsuduki, H. Kawabata, \& S. Hagiwara, Cognitive psychology: Brain, modeling and evidence (pp. 238-239). Tokyo: Yuhikaku.

Ito, M., \& Okabe, D. (2005b). Technosocial situations: Emergent structuring of mobile E-mail use. In M. Ito, D. Okabe, \& M. Matsuda (Eds.), Personal, Portable, Pedestrian: Mobile phones in Japanese life (pp. 257-273). Cambridge: The MIT Press.

Jungle. Inc. (2009) Keitai-master MX ver4.5 [Computer software].

Kadono, K., \& Nishimoto, K. (2009). A mail system that conveys information on editing process of a mail as implied messages. IPSJ Journal, 50(1), 254-267.

Katayama, A. (2003). A study on digitization of making sentences by using information instruments. Kyōiku Jōhō Kenkyū, 18(4), 13-20.

Kato, S., Kato, Y., Kobayashi, M., \& Yanagisawa, M. (2007). Analysis of the kinds of emotions interpreted from the emoticons used in e-mail. Kyōiku Jōhō Kenkyū, 22(4), 31-39.

Kato, Y., Kato, S., \& Akahori, K. (2006a). Analysis of emotional aspects in e-mail communication by mobile phone with a teacher or a friend. Kyōiku Jōhō Kenkyū, 21(3), 3-12.

Kato, Y., Kato, S., \& Akahori, K. (2006b). Surveys of occurrence of anger in e-mail communication by mobile phone. Kyōiku Jōhō Kenkyū, 22(2), 35-43.

Kimura, M. (2002). Expressions which depend on the medium: The case of mobile phone e-mail. Reports of the Osaka Shoin Women's University Japanese Language Research Center, 10, 35-48.

Kitani, Y. (2003). A study on the attitude of college students using mobile mail. Studies of Hiroshima Shüdō University, Research Society of the Humanities, 44(1), 341-371.

Kurosumi, K., \& Fukada, H. (2005). Influence of sex and gender on cellular phone call and cellular phone mail. Hiroshima Psychological Research, 5, 69-92.

Miyake, K. (2002). Young people's mobile telephone e-mail use and human relationships. Bulletin of Ogaki Women's College, 43, 49-59.

Miyake, K. (2003). The communication space of e-mail and language. Kosei Hogo, 54(4), 28-31.

Nakamura, I. (2003). Loneliness and the uses of the Short Message Service (SMS). Matsuyama University Review, 14(6), 85-99. https://doi.org/10.1111/ j.1083-6101.2003.tb00356.x

Oe, H. (2007). The meaning of letters among a variety of media: A comparative study of letters and mobile phone mail based on empirical data analysis. Journal of the Japan Information-culture Society, 14(1), $60-66$. 
Ono, S., \& Tokuda, K. (2005). The consciousness and reality of emoticon use in mobile e-mail among high school students, university students and housewives. The Science of Reading, 49(1), 22-32.

Riviere, C. A., \& Licoppe, C. (2005). From voice to text: Continuity and change in the use of mobile phones in France and Japan. In R. Harper, L. Palen, \& A. Taylor (Eds.), The inside text: Social, cultural and design perspectives on SMS (pp. 103-126). Dordrecht: Springer. https://doi.org/10.1007/1-4020-3060-6_6

Sato, K., Kato, Y., \& Kato, S. (2008). Exploring the impact of social presence as socio- psychological distance to the emotional strategy on mobile phone Email communication. Research report of JET Conferences, 8(2), 87-94.

Suzuki, A. (2005). Mobile-phone text messages as casual greetings: The sense of distance on the close relationship. International Media and Communication Journal, 3, 27-40.

Tachikawa, Y. (2005). The use of emoticons in mobile e-mail by youth: A text analysis of e-mail. Gobun, 122, 108-123.

Takahashi, Y., Fukada, H., \& Akimitsu, K. (2006). Effect on the receiver's state-anxiety by the sender's use of emoticon, the receiver's sex, and the receiver's trait-anxiety under the condition of using a cellular phone mail . Hiroshima Psychological Research, 5, 93-107.

Tomari, S. (2004). The relationship between behavior of message exchange by mobile mail and college life adjustment. Otsuma Women's University Bulletin of Faculty of Human Relations, 5, 25-39.

Tsuji, D. (2003). Summary report on a questionnaire survey of young people's communications and relationships with friends and parents. Bulletin of the Faculty of Sociology, Kansai University, 34(3), 373-389.

Uchida, Y. (2004). A study on "media-practice" of cell phone texting by youths: The influences of technical characteristics, "Double de-context nature". Studies in Ikuei Junior College, 21, 59-77.

Wooffitt, R. (2005). Conversation analysis and discourse analysis: Comparative and critical introduction. London: SAGE Publications. https://doi.org/10.4135/9781849208765

Yamaguchi, H., \& Joh, H. (2000). The role of emoticons in the electronic community. Bulletin of the Faculty of Human Developent, Kobe University, 8(1), 131-146.

Yamanishi, Y. (2007). Communication by written language among female university students: from the viewpoint of comparison of gender differences in media differences. Gobun, 128, 76-94.

\section{Copyrights}

Copyright for this article is retained by the author(s), with first publication rights granted to the journal.

This is an open-access article distributed under the terms and conditions of the Creative Commons Attribution license (http://creativecommons.org/licenses/by/4.0/). 